\title{
SEMINOMA IN UNDESCENDED INGUINAL TESTIS: A RARE CASE WITH REVIEW OF LITERATURE
}

\author{
Mohan A. Joshi' ${ }^{1}$ Richa S. Patel2 ${ }^{2}$ Ranjit Kamble 3 , Bankat Phad ${ }^{4}$ \\ 1 Professor and In Charge of GESS, Department of General Surgery, LTM Medical College and General Hospital, Mumbai. \\ 2SMO (Speciality Medical Officer), Department of General Surgery, LTM Medical College and General Hospital, Mumbai. \\ ${ }_{3}^{3}$ Assistant Professor, Department of General Surgery, LTM Medical College and General Hospital, Mumbai. \\ ${ }_{4}^{4}$ Assistant Professor, Department of General Surgery, LTM Medical College and General Hospital, Mumbai.
}

\section{BACKGROUND}

ABSTRACT

A rare case of testicular tumour in an undescended testis is reported here. A 20 years old patient presented with a large right inguinal swelling. He was a cryptorchid, had hypospadiasis and micropenis. Sonography and CT scan revealed a testicular tumour in undescended right inguinal testis. Patient was treated with high inguinal orchidectomy.

\section{KEYWORDS}

Undescended Testis, Cryptorchidism, Testicular Tumour, Hypospadiasis.

HOW TO CITE THIS ARTICLE: Joshi MA, Patel RS, Kamble R, et al. Seminoma in undescended inguinal testis: a rare case with review of literature. J. Evolution Med. Dent. Sci. 2016;5(102):7503-7505, DOI: 10.14260/jemds/2016/1698

\section{BACKGROUND}

The undescended testis are common paediatric surgical problem. It is extremely rare in adults with an incidence of unilateral testis being $0.3-0.8 \%$.(1) $^{1}$ The age of orchidopexy has diminished in present time. Right sided testicular undescend for unknown reasons is common than left. Bilateral undescend is not as common as unilateral undescend. The inguinal undescended testis is 7 times more prone and retroperitoneal undescended (abdominal undescended) testis is 36 times more prone for tumour formation than their contralateral descended testis.(1) Though tumorigenesis is the most lethal complication of undescend of testis, other complications like torsion are more frequently seen. We present here a rare case of hypospadiasis, micropenis and untreated cryptorchidism developing in inguinal testicular tumour at the age of 20 , histopathology of which was reported as seminoma after surgery.

\section{CASE REPORT}

A male aged 20 years presented with a painless, progressive swelling in the right inguinal region since 2 months. On careful examination of the patient, he had a large swelling of $12 \mathrm{~cm} \mathrm{x}$ $13 \mathrm{~cm}$ in the right inguinal region, which was firm to hard in consistency (Figure 1). Patient had bilateral undescended testis (cryptorchid), hypospadiasis and micropenis. Abdominal examination did not reveal any abdominal lump or organomegaly and examination of left supraclavicular fossa did not reveal any lymph nodes. His blood chemistry was normal, tumour markers were not done. Sonography revealed a solid tumour of $12 \mathrm{~cm} \times 13 \mathrm{~cm}$ underneath the external oblique in the right inguinal canal. The left testis could not be located in the left inguinal canal or abdomen. Chest skiagram was normal. CT scan revealed a large right inguinal solid

Financial or Other, Competing Interest: None.

Submission 16-11-2016, Peer Review 10-12-2016,

Acceptance 16-12-2016, Published 22-12-2016.

Corresponding Author:

Dr. Mohan A. Joshi,

Professor of Surgery,

Lokmanya Tilak Municipal Medical College,

Sion, Mumbai-400022.

E-mail:mohansion@gmail.com, patelricha1810@gmail.com

DOI: $10.14260 /$ jemds $/ 2016 / 1698$

\section{(c) (i) $\odot$}

tumour (? undescended testis) and the left testis was not seen (Figure 2). There were no abdominal lymph nodes. A clinical diagnosis of testicular tumour in an undescended testis was made. Patient was subjected to surgery with an inguinal incision. It revealed a large testicular tumour in an undescended testis in inguinal canal (Figure 3). The tumour was fleshy and hyperaemic. The cord structures were ligated at deep inguinal ring and a high orchidectomy was carried out. Capsule of tumour was intact. The wound was closed in layers. Patient had an uneventful recovery and was sent home on post-operative day 5. Patient followed up periodically and 3month follow-up revealed no clinical or sonological evidence of metastasis. The histopathology report revealed a seminoma.

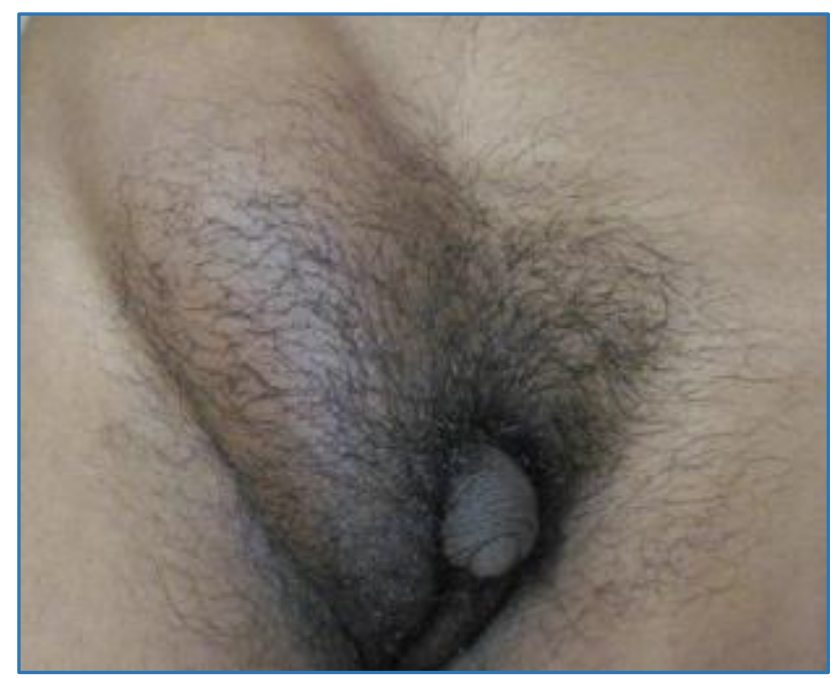

Figure 1. A large lump in the right inguinal region, patient also has bilateral undescended testis (Cryptorchidism), hypospadiasis and micropenis 


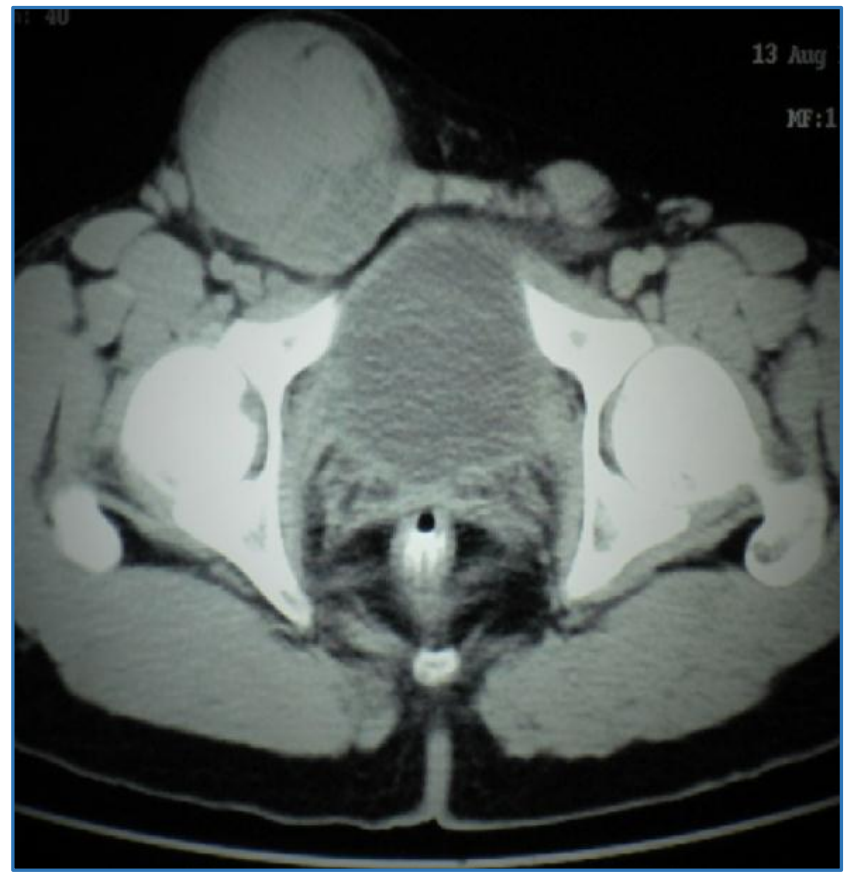

Figure 2. CT scan showing a solid tumor in the right inguinal region, no testis found on the left side

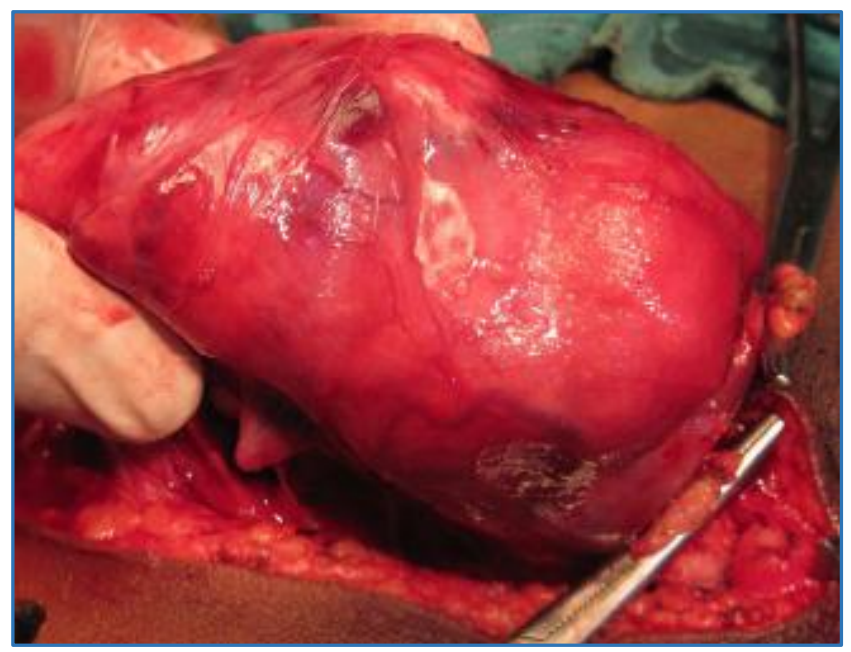

Figure 3. Intraoperative photograph of the patient, a large hyperaemic and fleshy testicular tumor on the right side

\section{DISCUSSION}

Cryptorchidism results from the abnormal formation and descent of the testes. The testes form from the genital ridges, which lie on both sides of the midline and extend from T6 through S2 vertebrae in the developing embryo. Between the $7^{\text {th }}$ and $12^{\text {th }}$ weeks of gestation, the testes under the influence of testosterone secreted from the Leydig cells begin their descent into the pelvis. They remain near the deep inguinal ring until the $7^{\text {th }}$ month of gestation, when they begin their descent through the inguinal canal into twin scrotal sacs. Passage through the inguinal canal is aided by both the processus vaginalis and the shortening of the gubernaculum. The testes remain retroperitoneal throughout their descent, but are intimately associated with the posterior wall of the processus vaginalis.

Undescended testis is present in approximately 2 - 5\% of full-term neonates and approximately $0.8 \%$ of infants at 1 year of age. There can be bilateral undescended testes or cryptorchidism. It is seen only in $10 \%$ of these patients, i.e. 0.2 - $0.5 \%$ full term neonates. $(2,3,4)$ Because of its association with other urinary tract abnormalities, cryptorchidism is thought to be one manifestation of a generalised defect in genitourinary embryogenesis. Other associated malformations include renal agenesis or ectopias, ureteral duplications, seminal vesicle agenesis or cysts, and hypospadiasis.(5-9) Cryptorchidism is also associated with infertility and is a well-recognised risk factor for testicular carcinoma. Approximately, $90 \%$ of these tumours are seminomas, especially those that occur in the abdominally located testis. Although, the overall incidence of cryptorchidism is low $(<1 \%)$, a history of an undescended testis is present in $3.5 \%-14.5 \%$ of patients of testicular tumours. ${ }^{(9)}$ The pathophysiology of malignant transformation in these testes is not completely understood. One hypothesis is that cryptorchidism is not merely incomplete descent of testes, but rather it reflects a generalised defect in embryogenesis and results in bilateral dysgenetic gonads. An embryologic defect in testicular formation is supported by several important clinical observations. The most compelling of these is that risk for testicular carcinoma is not limited to the undescended testis, but extends to the contralateral testis even if it is normally descended. Thus, the increased risk of carcinoma cannot be attributed to local environmental factors, such as increased temperature in the abdomen versus the scrotum. While it is true that the risk of carcinoma increases with the degree of ectopy - intraabdominal testes are at a 6 times greater risk of malignancy than those in the inguinal canal.(1) This also supports the theory if it is assumed that the greatest degree of ectopy reflects the greatest perturbation of embryogenesis. The defective embryogenesis hypothesis is further supported by the observation that orchidopexy, even at an early age does not appreciably decrease the risk of developing a tumour.(9) The majority of cryptorchid testes lie distal to the external inguinal ring and are palpable. Nonpalpable testes are most commonly located within the inguinal canal, but they can be located anywhere along the path of descent from the abdomen. Testicular agenesis has been reported to be present in $15 \%-63 \%$ of patients with a non-palpable testis. $(3,10)$ The distinction between agenesis and maldescent is critical, as orchidopexy should be performed in all patients with undescended testes. This usually is performed between 1 and 2 years of age. If performed later, the testis will have undergone marked morphologic change with fibrosis and collagen deposition adversely affecting spermatogenesis and fertility.(11) While orchidopexy improves fertility, it does not alter the risk of developing a carcinoma.(1)

A study published in Turkish Journal found that the presence of abnormal external genitalia, abdominal testes and abnormal karyotype was associated with increased risk of not only testicular germ cell tumours but also extragonadal germ cell tumours,(12) which holds true even in this case where patient had hypospadiasis and micropenis associated with cryptorchidism. However, in this case he turned out to have a tumour in an inguinal undescended testis. The left testis as mentioned before was not found clinically or radiologically. No attempt had been made to explore the inguinal region and investigate the patient further in order to locate the left testis by means of a laparoscopy or laparotomy or by magnetic resonance imaging plus venography as has been recommended by Lam et al. 
This case is rare, in that a testicular tumour has been rarely ever documented in an inguinal testis, although the theoretical risk of malignancy in an inguinal testis has been estimated to be $9 \%$. As mentioned above not only is the undescended testis dysgenetic, but its lymphatic drainage is also altered after orchidopexy, therefore it becomes likely that carcinoma of such a testis will metastasise to inguinal or pelvic lymph nodes.(1)

\section{CONCLUSION}

Testicular tumour in an undescended testis presenting as an inguinal mass is a very rare presentation. Seminomas are the most common tumour seen in undescended testis. Undescended testes, other urogenital abnormalities (Hypospadiasis, micropenis) and an abnormal karyotype are known to be associated with an increased risk of testicular malignancy. Orchidopexy does not decrease the risk of malignancy, but helps in reducing the incidence of infertility. Orchidopexy is recommended between 1 to 2 years of age and definitely before 10 years of age. Testicular biopsy is recommended at the time of orchidopexy to detect carcinoma in situ/carcinoma. The treatment of undescended testis by orchidopexy should take into consideration that orchidopexy alters the lymphatic drainage of the testis predisposing to inguinal and pelvic lymph node metastasis.

\section{REFERENCES}

1. Sheldon CA. Undescended testis and testicular torsion. Surgical Clin North Am 1985;65(5):1303-29.

2. Friedland GW, Chang P. The role of imaging in the management of impalpable undescended testis. AJR Am J Roentgenol 1988;151(6):1107-11.
3. Frush DP, Sheldon CA. Diagnostic imaging for pediatric scrotal disorders. Radiographics 1998;18(4):969-85.

4. Rajfer J, Walsh PC. Testicular descent. Normal and abnormal. Urol Clin North Am 1978;5(1):223-35.

5. Pappis $\mathrm{CH}$, Argianas SA, Bousgas D, et al. Unsuspected urological anomalies in aymptomatic cryptorchid boys. Pediatr Radiol 1988;18(1):51-3.

6. Schlegel PN, Shin D, Goldstein M. Urogenital anomalies in men with congenital absence of the vas deferens. J Urol 1996;155(5):1644-8.

7. Cortes D. Cryptorchidsm: aspects of pathogenesis, histology and treatment. Scand J Urol Nephrol Suppl 1998;196:1-54.

8. Flageat J, Vicens JL, Metges PJ. Seminoma on ectopic testis associated with renal agenesis. J Radiol 1982;63(12):7635.

9. Ulbright TM, Amin MB, Young RH. Miscellaneous primary tumors of testis, adnexa and spermatic cord. In: Rosai J, Sobin LH. eds. Atlas of tumor pathology, fasc 25, ser 3. Washington, DC: Armed Forces Institute of Pathology 1999:235-366.

10. Weiss RM, Seashore JH. Laparoscopy In the management of the nonpalpable testis. J Urol 1987;138(2):382-4.

11. Kier R, McCarthy S, Rosenfield AT, et al. Nonpalpable testes in young boys: evaluation with MR imaging. Radiology 1988;169(2):429-33.

12. Cortes D, Thorup J, Petersen BL. Testicular neoplasia in undescended testes of cryptorchid boys-does surgical strategy have an impact on the risk of invasive testicular neoplasia? The Turkish Journal of Pediatrics 2004;46 Suppl:35-42. 